\title{
Immunoglobulin classes in plasma cells of the synovial membrane in chronic inflammatory joint disease
}

\author{
PETER A REVELL AND VIVIEN J MAYSTON \\ From the Bone and Joint Research Unit, The London Hospital Medical College, Whitechapel, London
}

SUMMARY The histological features of the synovial membrane in rheumatoid arthritis (RA) are shared by other chronic inflammatory joint diseases, so that diagnostic differentiation is impossible. Examination of the immunoglobulin class in the plasma cells present in inflamed synovial membranes, however, has shown differences. Synovial membranes from 12 patients with seropositive RA, eight with seronegative RA, eight with ankylosing spondylitis, five with psoriatic arthritis, and three with Reiter's syndrome have been compared by peroxidaseantiperoxidase (PAP) staining for immunoglobulin classes on routinely paraffin wax embedded sections. There were no significant differences in the percentages of plasma cells containing IgG or IgA between the diseases studied. There were, however, significantly more plasma cells containing IgM in patients with seropositive RA (2-34\%) compared with those with seronegative RA $(0-10 \% ; p<0 \cdot 002)$ and with other chronic synovitides $(0-9 \% ; p<0 \cdot 002)$. The results show that it is possible to distinguish seropositive RA from other chronic inflammatory joint diseases by PAP staining for immunoglobulin classes in the plasma cells present in the inflamed synovial membrane.

Key words: rheumatoid arthritis, chronic synovitis, synovium.

The synovial membrane in rheumatoid arthritis is infiltrated by lymphocytes and often shows the presence of lymphoid follicles and numerous plasma cells. Various studies have shown that these appearances and other features, such as fibrin deposition and synovial intimal cell hyperplasia, are shared by other chronic inflammatory joint diseases, for example, ankylosing spondylitis, Reiter's syndrome, and psoriatic arthritis, ${ }^{1-5}$ so that distinguishing between diseases in a synovial biopsy is impossible. In a previous study of the synovial membrane in ankylosing spondylitis we examined the immunoglobulin classes present in plasma cells and compared these with the classes found in rheumatoid arthritis. ${ }^{4}$ There were significantly fewer plasma cells secreting IgM in ankylosing spondylitis than in rheumatoid arthritis, and it was suggested that this finding might provide a way of differentiating between ankylosing spondylitis and other chronic synovitides for diagnostic purposes. We have now obtained synovial

Accepted for publication 9 October 1985.

Correspondence to Dr Peter A Revell, Bone and Joint Research Unit, The London Hospital Medical College, Whitechapel, London E1 2AD. tissue from other cases of chronic inflammatory joint disease, performed immunohistochemical studies, and wish to report our findings.

\section{Materials and methods}

Thirty six samples of synovial membrane were obtained from patients with chronic inflammatory joint disease. The tissue was derived from synovial biopsy specimens or at the time of joint surgery. The clinical details of the cases are outlined in Table 1. The rheumatoid patients were divided into seropositive and seronegative groups according to the results of the latex test for rheumatoid factor (antiglobulin) activity. There were 12 patients with seropositive and eight with seronegative rheumatoid arthritis. The other synovitides were present in patients with well characterised clinical features of ankylosing spondylitis (eight cases), psoriatic arthritis (five cases), or Reiter's syndrome (three cases).

HISTOLOGICAL PROCESSING AND STAINING METHODS

All the synovial tissue from our own hospital was 
Table 1 Clinical details of cases studied

\begin{tabular}{llllll}
\hline & $R A^{+*}$ & $R A^{-*}$ & $A S^{*}$ & $P S A^{*}$ & $R S^{*}$ \\
\hline Age range (years) & $45-70$ & $13-55$ & $18-50$ & $15-58$ & $22-33$ \\
Sex & $2 \mathrm{M}$ & $1 \mathrm{M}$ & $6 \mathrm{M}$ & $2 \mathrm{M}$ & $3 \mathrm{M}$ \\
Joint involved & $10 \mathrm{~F}$ & $7 \mathrm{~F}$ & $2 \mathrm{~F}$ & $3 \mathrm{~F}$ & 2 knees \\
& 8 knees & 4 knees & 1 knee & 3 knees & 1 ankle \\
& 2 elbows & 2 hands & 1 ankle & 1 elbow & \\
& 1 wrist & 1 wrist & 6 hands & &
\end{tabular}

${ }^{*} \mathrm{RA}^{+}=$seropositive rheumatoid arthritis; $\mathrm{RA}^{-1}=$ seronegative rheumatoid arthritis; $\mathrm{AS}=$ ankylosing spondylitis; PsA=psoriatic arthritis; RS= Reiter's syndrome.

fixed in $10 \%$ formol saline, and other laboratories that had submitted material confirmed that their samples had been fixed in a similar way. All the samples were processed on automatic tissue processors, embedded in paraffin wax, and sectioned at $5 \mu \mathrm{m}$ thickness. Sections were stained with haematoxylin and eosin and by the peroxidase-antiperoxidase (PAP) technique to show the presence of IgG, IgA, and IgM immunoglobulin classes. Rabbit antihuman IgG, IgA, and IgM, normal swine serum, and swine antirabbit peroxidase were used. Reagents were obtained from Dakopatts (Mercia Brocades Ltd). The primary antisera were used at optimal dilutions (IgG 1:800; IgA and IgM 1:400) and swine antirabbit antiserum at a dilution of 1:20. Specificity of the antisera was checked against tumours contain-i ing plasma cells of known immunoglobulin specificity or (IgG plasmacytoma, IgA myeloma, IgM lympho-: plasmacytic malignant lymphoma). Endogenouscr peroxidase was inhibited by treatment of sections $ᄋ$ with freshly prepared $0.5 \% \quad \mathrm{H}_{2} \mathrm{O}_{2}$ in methanolfor 30 minutes. The peroxidase reaction was 3 developed with 3,3-diaminobenzidine tetrahydrochloride (DAB) (BDH Chemicals). Positive control $\overrightarrow{0}$ material was used throughout and was provided byọ paraffin processed tonsil.

EXAMINATION OF SECTIONS

The number of plasma cells containing a particularo immunoglobulin type was obtained by counting 500 요

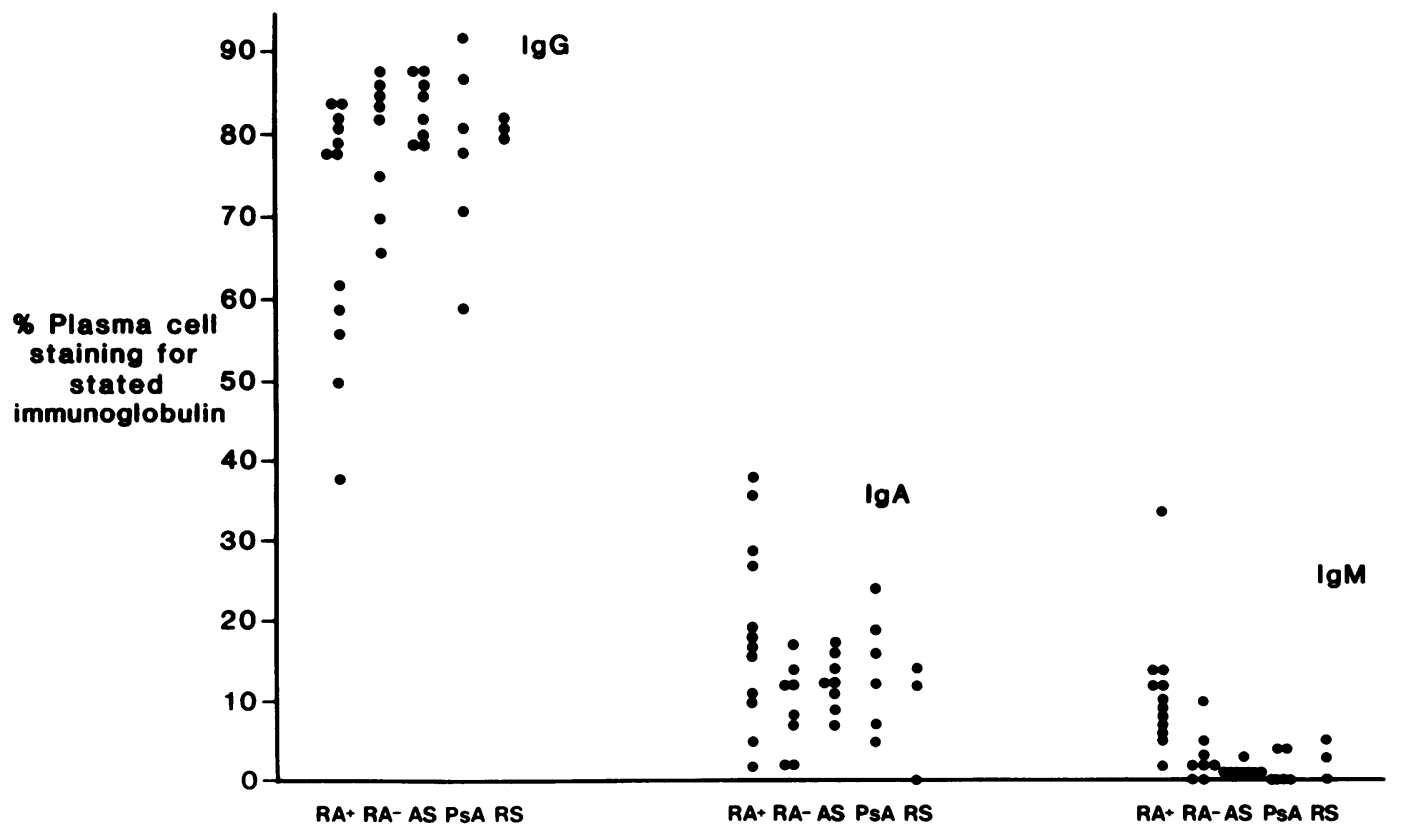

Fig. 1 Percentages of plasma cells staining for $\operatorname{Ig} G, \operatorname{Ig} A$, and $\lg M$ in the synovial membrane in different chronic synovitides. 
Table 2 Percentages of plasma cells containing different immunoglobulin classes in the stated chronic synovitides

\begin{tabular}{|c|c|c|c|c|}
\hline \multirow[t]{2}{*}{ Diagnosis } & \multirow{2}{*}{$\begin{array}{l}\text { No of } \\
\text { cases }\end{array}$} & \multicolumn{3}{|c|}{ Percentage (range) } \\
\hline & & $\operatorname{Ig} G$ & $\operatorname{Ig} A$ & $\lg M$ \\
\hline $\mathrm{RA}^{+*}$ & 12 & $38-84$ & $2-38$ & $2-34(a) \dagger$ \\
\hline $\mathbf{R A}^{-}$ & 8 & $66-88$ & $2-17$ & $0-10$ (b) $\dagger$ \\
\hline AS & 8 & $79-88$ & $7-17$ & $0-3$ (c) \\
\hline PsA & 5 & $59-92$ & $5-24$ & $0-9$ (c) ${ }^{\dagger}$ \\
\hline RS & 3 & $80-83$ & $0-14$ & $0-5(c)$ \\
\hline
\end{tabular}

${ }^{*}$ For abbreviations see Table 1.

† Mann-Whitney U test, a $v \mathrm{~b}, \mathrm{p}<0.002 ; \mathrm{a} v \mathrm{c}, \mathrm{p}<0.002$.

cells in the subintimal cellular infiltrate using an eyepiece graticule at high magnification. Exactly the same areas were chosen and counted in adjacent serial sections. Errors due to differences in sampling within a section were kept to a minimum by this method, and reproducible results were obtained. Only those cells morphologically distinguishable as plasma cells were counted.

\section{Results}

Histological examination of synovial tissue showed the presence of a diffuse lymphocytic infiltrate, formation of lymphoid follicles, perivascular lymphocytic collections, and plasma cells in all the biopsy specimens. There were no distinguishing features recognisable when the sections were examined without knowledge of diagnosis, scored for the presence of features on a semiquantitative basis, and the appearances of particular diseases compared.

Staining of paraffin sections for immunoglobulin classes showed the presence of plasma cells containing $\operatorname{IgG}, \operatorname{IgA}$, and $\operatorname{IgM}$ in the cellular infiltrate of the synovial membranes. The percentages of plasma cells containing different classes of immunoglobulin are shown in Fig. 1 and the ranges for the values obtained are shown in Table 2. Statistical analysis of the results showed no significant difference in the percentages of plasma cells containing $\operatorname{IgG}$ or $\operatorname{IgA}$ between groups. The level of plasma cells containing IgM was significantly higher in the seropositive rheumatoid arthritis synovia than in all the other cases either considered separately or in combination (Table 2, p $<0.002$, Mann-Whitney $U$ test). No significant difference was demonstrable between seronegative rheumatoid arthritis and the other nonrheumatoid chronic inflammatory joint diseases.

\section{Discussion}

Various studies have compared the histological appearances of the synovial membrane by conventional staining methods and failed to show a useful method of distinguishing between disease processes. ${ }^{1-4}$ The presence of different immunoglobulins in synovial plasma cells has been described by numerous workers in rheumatoid arthritis. ${ }^{4-10} \operatorname{IgA}$ has been noted in synovial plasma cells in both rheumatoid arthritis and ankylosing spondylitis, ${ }^{4}$ and the present study confirms the presence of all three immunoglobulins in synovial plasma cells. Several different methods have been used to show the presence of antiglobulin (rheumatoid factor) activity in the synovial membrane and this has been localised to the plasma cells..$^{511-13}$ We were unable to show the presence of rheumatoid factor in plasma cells of synovium in ankylosing spondylitis in a previous study. ${ }^{14}$

There are various techniques for demonstrating rheumatoid factor activity, all of which require fresh frozen sections of synovial tissue. Details about findings in chronic synovitides other than rheumatoid arthritis and ankylosing spondylitis are not available, so that it is not at present possible to use the demonstration of rheumatoid factor as a routine method of discriminating between diseases.

Comparison of immunoglobulin classes in rheumatoid and ankylosing spondylitic synovium showed a significantly lower level of cells containing IgM in the latter. ${ }^{4}$ Only $7 \%$ of synovial membranes in psoriatic arthritis showed the presence of plasma cells containing IgM, ${ }^{10}$ though the percentages of such cells in individual cases was not recorded. The present study shows the low percentages of plasma cells containing IgM in the synovial membrane of individual cases of psoriatic arthritis. The results show that there are significantly more plasma cells containing IgM in seropositive rheumatoid arthritis than in all the other conditions investigated. This is perhaps not surprising in view of the fact that classical rheumatoid factor is IgM antibody. We believe, nevertheless, that we have shown that the simple procedure of staining for immunoglobulin classes in routine paraffin sections presents a useful way of separating seropositive rheumatoid arthritis from the other chronic synovitides and provides, for the first time, a simple method of differentiating this condition from others by synovial histopathology.

\section{References}

1 Goldenberg D L, Cohen A S. Synovial membrane histopathology in the differential diagnosis of rheumatoid arthritis, gout, pseudogout, systemic lupus erythematosus, infectious arthritis and degenerative joint disease. Medicine (Baltimore) 1978; 57: 239-52.

2 Cooper N S, Soren A, McEwen C, Rosenberger J L. Diagnostic specificity of synovial lesions. Hum Pathol 1981; 12: 314-28. 
3 Rosenberger J L, Cooper N S, Soren A, McEwen C. A statistical approach to the histopathologic diagnosis of synovitis. Hum Pathol 1981; 12: 329-37.

4 Revell P A, Mayston V. Histopathology of the synovial membrane of peripheral joints in ankylosing spondylitis. Ann Rheum Dis 1982; 41: 579-86.

5 Mellors R C, Heimer R, Corcos J, Korngold L. Cellular origin of rheumatoid factor. $J$ Exp Med 1959; 110: 875-86.

6 Fish A J, Michael A F, Gewurz H, Good R A. Immunopathologic changes in rheumatoid arthritis synovium. Arthritis Rheum 1966; 9: $267-80$.

7 Friis J. Immunohistochemical demonstration of rheumatoid factor (RF) in alcohol-fixed synovial tissue from patients with rheumatoid arthritis (RA). Acta Pathol Microbiol Scand 1969; 75: 71-84.

8 Munthe E, Natvig J B. Immunoglobulin classes, subclasses and complexes of $\mathrm{IgG}$ rheumatoid factor in rheumatoid plasma cells. Clin Exp Immunol 1972; 12: 55-70.
9 Mestecky J, Miller E J. Presence of antibodies specific to cartilage-type collagen in rheumatoid synovial tissue. Clin Exp Immunol 1975; 22: 453-6.

10 Fyrand $O$, Mellbye $O \mathrm{~J}$, Natvig J B. Immunofluorescence studies for immunoglobulins and complement $\mathrm{C} 3$ in synovial joint membranes in psoriatic arthritis. Clin Exp Immunol 1977; 29: $422-7$.

11 Bonomo L, Tursi A, Gilliardi U. Distribution of the antigamma globulin factors in the synovial membrane and other tissues in various diseases. Ann Rheum Dis 1968; 27: 122-9.

12 Kaplan M H. The site of formation of rheumatoid factor. Arthritis Rheum 1963: 6: 475-80.

13 McCormick J N. An immunofluorescence study of rheumatoid factor. Ann Rheum Dis 1963; 22: 1-10.

14 Davies P G, Revell P A, Mayston V, Johnston G D, Holborow E J. Immunofluorescence studies of rheumatoid factor in rheumatoid arthritis (RA) and ankylosing spondylitis (AS) synovial membrane. Ann Rheum Dis 1983; 42: 220. 